\title{
VEGETATED FORESHORES AS COASTAL PROTECTION STRATEGY: COPING WITH UNCERTAINTIES AND IMPLEMENTATION
}

\author{
Bas Borsje, University of Twente, The Netherlands, b.w.borsje@utwente.nl \\ Pim Willemsen, University of Twente, The Netherlands, p.w.j.m.willemsen@utwente.nl \\ Suzanne Hulscher, University of Twente, The Netherlands, s.j.m.h.hulscher@utwente.nl
}

\begin{abstract}
Worldwide, hard structures are used as coastal protection measure. These structures are static and do not respond to the changing climate like sea level rise and increasing storminess. Moreover, the energy released during extreme events is hardly dissipated, resulting in enormous losses and damage. Recently, the use of soft solutions in front of hard structures is more and more proposed - but not applied - as sustainable coastal protection measure. These measures allow for economic growth in coastal regions, which are the world's most valuable areas. Promising Building with Nature solutions for flood protection, such as vegetated foreshores, inherently have a dynamic nature. Therefore there is a relatively large degree of uncertainty with respect to their contribution to flood protection. This hampers innovation and the implementation of vegetated foreshores in flood risk management worldwide.
\end{abstract}

\section{RESARCH QUSTIONS AND METHODOLOGY}

The central scientific research question is: how, and how much can vegetated foreshores contribute to flood risk reduction? The project will lead to a better understanding of (uncertainties in) the functioning and stability of these ecosystems and the development of novel governance arrangements. This requires integration of knowledge from ecology, biogeomorphology, hydraulic engineering, and governance. By field observations on several sites within the Netherlands and flume measurements at $\mathrm{NIOZ}$ Yerseke we analyse fundamental ecological and physical processes for various types of wetland vegetation. The wave dampening by cordgrass and grassweed is measured for four years now continuously at two exposed locations in the South West of the Netherlands. Moreover, vegetation densities, vegetation heights and bed levels are measured every season at these two locations. Flume experiments on thresholds for collapse and establishment of vegetation allow us to link the physical forcing towards vegetation growth rules. These data are used to calibrate and validate hydrodynamic and morphodynamic modelling tools.

\section{MAIN FINDINGS}

To determine if vegetation can establish, the Windows of Opportunity (WoO) concept by Balke et al. (2011) is used. This theory states that plants require subsequently a short disturbance-free period to grow roots (WoO1); a period with calm hydrodynamic conditions (WoO2) and a period with tolerable high-energy events (WoO3). As plants are very sensitive to erosion and significant erosion occurs during relatively moderate events, this study defines the vegetation limits in terms of critical erosion depth (CED). The CED of Spartina anglica and Salicornia procumbens plants is determined with a wave flume. This shows that the CED depends mostly on previous bed level change, supporting the choice to define the WoO framework in terms of bed level dynamics.

A Delft3D model is set-up to predict the bed level dynamics and implement the WoO framework for a salt marsh situation. In this model erosion occurs, with a cliff forming around the high water line. Consequently, WoO1 and $\mathrm{WoO} 2$ and thereby vegetation establishment can only occur directly at the coast. This shows that it is essential for the stability of the salt marsh that wavebreaking measures are taken. Furthermore, the data from the experiment is used to calibrate and improve the WoO framework and thereby provides valuable information for future building with nature projects.

\section{OUTLOOK}

The project provides the knowledge, methods and tools required for the design and implementation of vegetated foreshores as a safe, ecologically desirable, and cost effective alternative in flood management. Strong cooperation with end-users from the private sector, government and non-governmental organizations is embedded in the project to enhance the implementation of our findings in practice. In the full-paper, we present a multidisciplinary research agenda how to address the uncertainties hampering application, how to develop probabilistic tools to derive failure chance in legally imposed terms and how to derive at suitable governance arrangements.

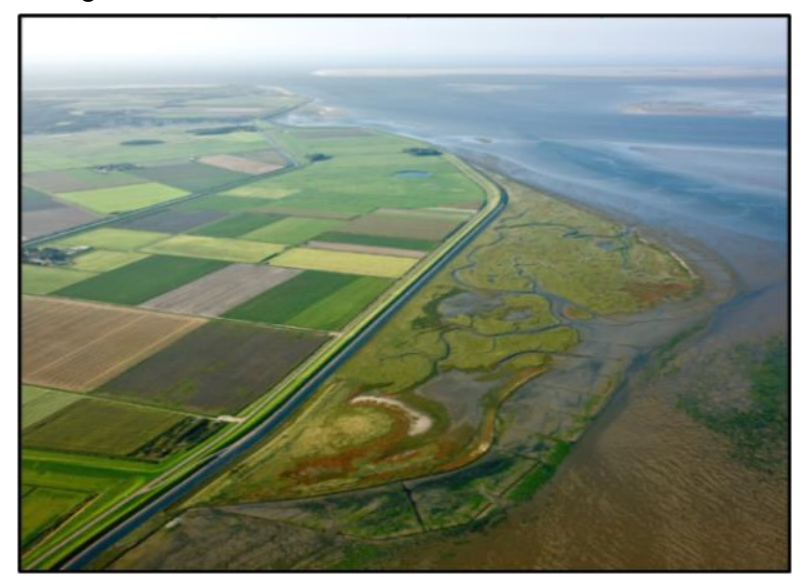

Figure 1. An example of a natural coastal wetland in front of a dike (Island Texel, The Netherlands).

\section{REFERENCES}

Balke, T., Bouma, T. J., Horstman, E. M., Webb, E.L., Erftemeijer, P. L., \& Herman, P. M. (2011). Windows of opportunity: thresholds to mangrove seedling establishment on tidal flats. Marine Ecology Progress Series, 440, 1-9. 